Results: The study was completed with 61 patients (108 hands). Extramedian symptoms were present in 31 patients ( 54 hands). Finger grip strength was lower, pain values evaluated with visual analogue scale were higher in these patients $(p<0.05)$. There was no statistically significant difference in electrophysiological and ultrasonographic parameters between two groups.

Conclusions: These results suggest that extramedian spread in CTS patients is more related to central and peripheral sensitization than peripheral causes. Disclosure of Interest: None declared

DOI: 10.1136/annrheumdis-2017-eular.6551

\section{AB1004 NOMENCLATURE ON MEDICAL, DIAGNOSTIC, AND THERAPEUTIC PROCEDURES IN RHEUMATOLOGY}

B. Yoldi ${ }^{1}$, M.A. Martin ${ }^{2}$, C. Plana ${ }^{3}$, A. Gómez ${ }^{4}$, M. Valero ${ }^{5}$, J.L. Andreu ${ }^{6}$, J.V. Moreno ${ }^{7} .{ }^{1}$ Rheumatolgy, Hospital Universitari Dexeus, Barcelona; ${ }^{2}$ Sociedad Española de Reumatología, Madrid; ${ }^{3}$ Rheumatology, Hospital Clínic Provincial, Barcelona; ${ }^{4}$ Rheumatology, Hospital Parc Taulí, Sabadell; ${ }^{5}$ Rheumatology, HM Hospitales; ${ }^{6}$ Rheumatology, Hospital Universitario Puerta del Hierro, Madrid; ${ }^{7}$ Rheumatology, Hospital Vall d'Hebron, Barcelona, Spain

Background: One of the missions of the Spanish Society of Rheumatology (SER) is to provide professionals involved with the necessary tools to ensure a better care for patients suffering from a rheumatic disease. Up to now, there is no benchmark that quantifies the complexity of medical acts in this specialty. Therefore, there is a need to adopt a physician activity scale that would allow assessment of their professional activity and skills regarding patient care.

Objectives: To compile a nomeclature of medical, diagnostic, and therapeutic procedures in the field of rheumatology; and to establish a hierarchical classification system according to a complexity index.

Methods: A list of care, diagnostic, and therapeutic acts was compiled based on the nomenclature created by Drs Fernandez and Olive. The hierarchical classification system was based on the construction of a complexity index which was calculated by two factors: time of completion and degree of complexity of each act. Time of completion was stated according to the document "Standards of Process Time and Patient Care Quality" by Dr Alonso. The degree of complexity of each rheumatologic act was agreed thanks to a panel of experts using a Delphi technique in two rounds. Subsequently, it was validated against a questionnaire which was sent to the 1144 partners of SER via its web.

Results: The total of included acts was 54 . The results obtained with the Delphi method tended to show a consensus of opinion (media $\sigma 2-\sigma 1=0.75-1.43=-0.68$, media IQR2 - IQR1 $=0.8-1.9=-1.1$ ). Furthermore, a validation of these results was carried out through a massive survey among the partners of SER. The survey results showed a high degree of agreement (at least 70.0 per cent of the partners agreed or strongly agreed with the complexity of each act).

The degree of complexity in successive visits was 100 . In the query section for consultations, the highest scores were obtained by first visit to hospitalized patient (366) and home visit (369). Regarding diagnostic techniques, the highest scores were obtained with biopsies: bone (465), sural nerve (416), and synovial (380). Also worth mentionioning the scores obtained by ultrasound scan (204), capillarioscopy (113) and densitometry (112). Regarding therapeutic techniques, intra-articular injection under sedation in children obtained a score of 388 ; while intra-articular injection with ultrasound control obtained a score of 163 . The clinical report of disability was agreed to have a score of 323 , and the expert report obtained a score of 370 .

Conclusions: This work has made it possible to create a nomenclature of 54 acts in Rheumatology where biopsies (bone, sural nerve, synovial), visits to hospitalized patients, home visits, infiltration under sedation in children, and expert reports are identified as the most complex acts. Musculoskeletal ultrasound is considered twice as complex as a successive visit, capillaroscopy, or bone densitometry. These results will make it possible to improve patient care and establish a solid and agreed foundation to negotiate the provision of public and private services.

Disclosure of Interest: None declared

DOI: 10.1136/annrheumdis-2017-eular.4353

\section{AB1005 HYPOTHYROID AND HYPERTHYROID STATUS WAS STRONGLY ASSOCIATED WITH MUSCULOSKELETAL ULTRASONOGRAPHIC ABNORMALITIES WITH ARTHRALGIA}

B.Y. Kim ${ }^{1}$, S.S. Kim ${ }^{2}$, J.R. Choi ${ }^{3}$, H.-S. Kim ${ }^{1} .{ }^{1}$ Department of Internal Medicine, Soonchunhyang University college of Medicine, Seoul; ${ }^{2}$ Department of Internal Medicine, Gangneung Asan Medical Center, Gangneung; ${ }^{3}$ Department of Internal Medicine, Pohang Saint Mary's Hospital, Pohang, Korea, Republic Of

Background: Thyroid dysfunction can cause musculoskeletal symptoms and sign. Ultrasonography is a useful tool for the evaluation of synovitis and is more accurate than clinical examination.

Objectives: The purpose of the study was to determine whether musculoskeletal ultrasonographic (MSUS) abnormalities were observed according to the state of thyroid disease.

Methods: Patients with thyroid disease were categorized as euthyroid, hypothyroid, or hyperthyroid status according to thyroid hormone levels and evaluated the association with MSUS abnormalities. In addition, the association of the presence of thyroid autoantibodies with MSUS abnormalities was also studied. In MSUS, an experienced rheumatologist examined the presence of synovial fluid, synovial hypertrophy, and grade of power doppler in the knee joint.

Results:

Table 1. Patient characteristics

\begin{tabular}{lc}
\hline & Patients $(\mathrm{n}=109)$ \\
\hline Age - mean \pm SD (years) & $58.2 \pm 13.0$ \\
Sex $-\mathrm{n}(\%)$ & $13(11.9)$ \\
$\quad$ Male & $96(88.1)$ \\
$\quad$ Female & $4(0-13)$ \\
Thyroid diseases duration - median (range), (years) & \\
Distribution of thyroid diseases - $\mathrm{n}(\%)$ & $61(56)$ \\
$\quad$ Euthyroid status & $11(10.1)$ \\
$\quad$ Hypothyroid status & $37(33.9)$ \\
$\quad$ Hyperthyroid status & $68(62.4)$ \\
Positive thyroid autoantibodies - $\mathrm{n}(\%)$ & $100(91.7)$ \\
Taking thyroid medication $-\mathrm{n}(\%)$ & $10(0-80)$ \\
Patient's Knee VAS (100mm) - median (range) & $72(66.1)$ \\
MSUS finding - $\mathrm{n}(\%)$ & $37(33.9)$ \\
$\quad$ Normal & \\
$\quad$ Abnormal & \\
\hline
\end{tabular}

109 consecutive patients who visited the endocrinology outpatient clinic and had thyroid disease with normal or abnormal thyroid function tests participated in the study. MSUS abnormalities were statistically significantly higher in hyperthyroid or hypothyroid status than in euthyroid status $(p<0.001)$. However, there was no statistically significant difference between hypothyroid status and hyperthyroid status. The presence of MSUS abnormalities with abnormal thyroid function was corrected according to the presence of radiological Knee osteoarthritis. Both hypothyroid and hyperthyroid status was still associated with MSUS abnormalities regardless of knee osteoarthritis. Visual analogue scale for knee pain was higher in patients with MSUS abnormalities $(p<0.001)$. But, there was no statistically difference of MGUS abnormalities with presence of thyroid autoantibodies.

Figure 1. It shows frequency of Abnormal MSUS finding according to thyroid status

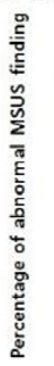

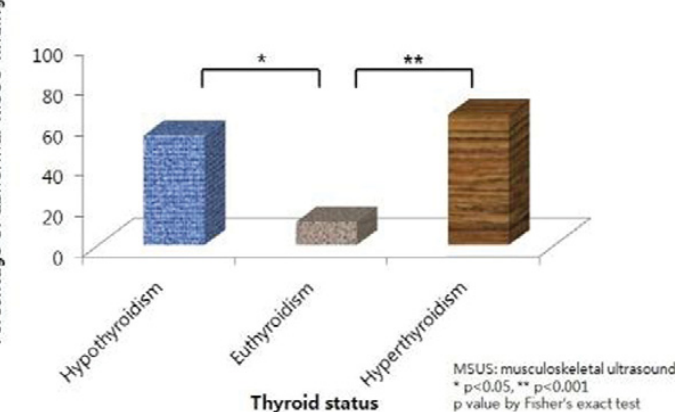

Conclusions: Both hypothyroid and hyperthyroid status was significantly associated with MSUS abnormalities with knee arthralgia. MSUS is a useful tool to detect clinically early joint abnormalities. We suggest that patients with diagnosed thyroid dysfunction and who remain uncontrolled, should assess the MSUS examination in patients with arthralgia. Moreover a thyroid function test for unexplained arthritis maybe warranted.

\section{References:}

[1] Cakir M, Samanci N, Balci N, et al. Musculoskeletal manifestations in patients with thyroid disease. Clin Endocrinol 2003;59:162-7.

[2] Wakefield RJ, Green MJ, Marzo-Ortega H, et al. Should oligoarthritis be reclassified? Ultrasound reveals a high prevalence of subclinical disease. Ann Rheum Dis 2004;63:382-5.

[3] Magni-Manzoni S, Epis O, Ravelli A, et al. Comparison of clinical versus ultrasound-determined synovitis in juvenile idiopathic arthritis. Arthritis Rheum 2009;61:1497-504.

[4] Karim Z, Wakefield RJ, Quinn M, et al. Validation and reproducibility of ultrasonography in the detection of synovitis in the knee: a comparison with arthroscopy and clinical examination. Arthritis Rheum 2004:50:387-94.

Disclosure of Interest: None declared

DOI: 10.1136/annrheumdis-2017-eular.3054

\section{AB1006 POWER-DOPPLER TECHNIQUE IN PAGET'S DISEASE OF BONE: A NEW MONITORING TOOL OF THERAPEUTIC RESPONSE. STUDY ON 43 PATIENTS}

C. Artusi ${ }^{1}$, C. Mastaglio ${ }^{2}$, C. Arnoldi ${ }^{2}$, V. Galbiati ${ }^{2}$, P.L. Meroni ${ }^{1} .{ }^{1}$ Chair and Division of Rheumatology, Gaetano Pini Institute, University of Milan, Milan; ${ }^{2}$ Unit of Rheumatology, Ospedale Moriggia-Pelascini, Gravedona (CO), Italy

Background: To date the evaluation of the disease activity and the monitoring of the therapeutic response of patients affected by Paget's disease of bone is based only on clinical and hematological data. However, in clinical practice the management of these patients is still challenging. Previous angiographic 